\title{
Transport of BC1 RNA in Hypothalamo-neurohypophyseal Axons
}

\author{
Henri Tiedge, ' An Zhou,, ${ }^{2, a}$ Niels A. Thorn, ${ }^{2}$ and Jürgen Brosius' \\ 'Fishberg Research Center for Neurobiology, Mount Sinai School of Medicine, New York, New York 10029 and \\ ${ }^{2}$ Department of Medical Physiology C, The Panum Institute, University of Copenhagen, and the Danish Government \\ Biotechnology Center for Signal Peptide Research, DK-2200 Copenhagen N, Denmark
}

\begin{abstract}
Ample evidence indicates that in nerve cells, several individual proteins are locally synthesized in postsynaptic domains in dendrites. By contrast, axonal terminals, at least in mammals, are generally thought to lack protein synthetic capacity. However, axonal nerve endings of the hypothalamo-neurohypophyseal tract have recently been shown to contain mRNAs encoding vasopressin, oxytocin, dynorphin, and neurofilament. In this report, we identify BC1 RNA, a small RNA polymerase III transcript that is specifically expressed in neurons, in hypothalamo-neurohypophyseal axons. BC1 RNA has previously been shown to be located in somatic and dendritic domains of various types of neurons in the rat nervous system. Here we present evidence to show that BC1 RNA, like several neuropeptide mRNAs, is axonally transported from magnocellular hypothalamic neurons to neurosecretory nerve endings in the posterior pituitary. $\mathrm{BC} 1$ RNA, which has been reported to be a component of a ribonucleoprotein particle, is thus colocalized with dendritic mRNAs in dendritic domains and with axonal mRNAs in axonal domains, respectively. Such colocalization is indicative of functional interactions of BC1 RNA with those mRNAs that are targeted to extrasomatic domains of nerve cells.
\end{abstract}

[Key words: axonal RNA, hypothalamus, neurosecretory terminals, pituitary, in situ hybridization, RNA transport]

A foremost concern in cell biology has been to understand how individual cellular components are directed to their respective local target sites. While classical concepts emphasize a specific transport and targeting of proteins, recent evidence indicates that the subcellular location of a number of proteins may be the result of local translation of their respective mRNAs. Differential intracellular sorting and targeting of specific RNAs has now been demonstrated in a variety of eukaryotic cell types. Such cells include, among others, oocytes, fibroblasts, epithelial cells, endothelial cells, and several types of glial cells (for ex-

\footnotetext{
Received Feb. 15, 1993; revised Apr. 20, 1993; accepted Apr. 28, 1993.

We thank Drs. A. Matus, R. Neve, and O. Steward for cDNA clones. Immunocytochemical control experiments were performed by A. Gazzaley. R. Woolley's expert assistance with illustrations is gratefully acknowledged. We thank Dr. F. Bloom for helpful comments on the manuscript. This work was supported by grants to J.B. (National Institute of Mental Health, MH 38819), to N.A.T. (The Alfred Benzon Foundation, The A. P. Moller \& Hustru Foundation), and to H.T. (Deutsche Forschungsgemeinschaft, HT 161/1-1; National Science Foundation, IBN-9210149).

Correspondence should be addressed to Henri Tiedge, Fishberg Research Center for Neurobiology, Mount Sinai School of Medicine, One Gustave L. Levy Place, New York, NY 10029.

a Present address: Department of Neuroscience, The Johns Hopkins University Medical School, Baltimore, MD 21205.

Copyright (C) 1993 Society for Neuroscience 0270-6474/93/134214-06\$05.00/0
}

amples, see Colman et al., 1982; Lawrence and Singer, 1986; Melton, 1987; Trapp et al., 1987; Webster et al., 1987; Berleth et al., 1988; Cheng and Bjerknes, 1989; Sarthy et al., 1989; Ephrussi et al., 1991; Hoock et al., 1991; Kim-Ha et al., 1991; Trimmer et al., 1991; Gavis and Lehmann, 1992). In these examples, various mRNAs have been shown to be colocalized with their cognate proteins in cellular domains where these proteins function, and such colocalization has been taken to indicate local "on-site" synthesis of those proteins. Direct mRNA transport has been documented in some of these cases, and "localizer" sequences have been identified within the 3 ' untranslated regions of some of those mRNAs (for review, see Kislauskis and Singer, 1992).

In nerve cells, various types of RNA have been shown to be located in dendritic domains: ribosomal RNAs (R. Kleiman, G. Banker, and O. Steward, personal communication); BC1 RNA, a neuron-specific RNA polymerase III transcript (Tiedge et al., 1991, 1992; see also below); and several mRNAs. Although most mRNAs in neurons seem to be restricted to the perikarya, a limited number of neuronal mRNAs have been identified in dendritic domains. These include the mRNA encoding the dendritic form of microtubule-associated protein 2 (MAP $2 a / b$; see Garner et al., 1988; Bruckenstein et al., 1990; Kleiman et al., 1990) and the mRN $\Lambda$ encoding the $\alpha$-subunit of $\mathrm{Ca}^{2+} /$ calmodulin-dependent protein kinase type II (CaM-KII; see Burgin et al., 1990; Benson et al., 1991). In addition, the mRNA for the amyloid precursor protein (APP) has been detected in proximal dendritic domains of developing hippocampal neurons in culture (Strong et al., 1990), and the mRNA encoding brain-derived neurotrophic factor (BDNF) has recently been identified in proximal dendritic segments of dentate granule cells during postnatal development (Dugich-Djordjevic et al., 1992). Active protein biosynthesis has been demonstrated in preparations of synaptosomes (also referred to as "synaptodendrosomes"; Rao and Steward, 1991) as well as in preparations of dendrites that had been physically isolated from hippocampal neurons in culture (Torre and Steward, 1992). The combined evidence thus supports the concept of local translation in dendrites, a design that may enable neurons to synthesize selected dendritic proteins close to postsynaptic sites where they are required (see Steward and Banker, 1992, for review).

While dendritic protein synthesis appears to be a rather ubiquitous design that may be employed by many different types of nerve cells, it is generally believed that mammalian axons, except in their most proximal segments, are devoid of protein synthetic machinery and would thus rely on import, via axoplasmic transport, of proteins from the cell body (for reviews, see Ginzburg, 1991; Steward and Banker, 1992). There may, 
however, be exceptions to this rule. Vasopressin, oxytocin, dynorphin, and neurofilament mRNAs have been detected in the posterior (neural) lobe of the pituitary (Murphy et al., 1989; Jirikowski et al., 1990; Lehman et al., 1990; McCabe et al., 1990; Mohr et al., 1991; Mohr and Richter, 1992) and in the infundibular stalk (Jirikowski et al., 1990; Mohr et al., 1991; Mohr and Richter, 1992). Following physical disconnection of the hypothalamo-neurohypophyseal tract, vasopressin- and oxytocin-encoding transcripts (only these mRNAs were analyzed) could no longer be detected in the posterior pituitary (Mohr et al., 1990). Similarly, the accumulation of vasopressin mRNA in the posterior pituitary could be prevented by intracerebroventricular injection of colchicine (Levy et al., 1990). Intron analysis indicated that non-neuronal cells of the posterior pituitary were devoid of primary vasopressin and oxytocin transcripts (Mohr et al., 1991). These data thus strongly suggest that several mRNAs, including neuropeptide-encoding transcripts, are axonally transported to the neurosecretory terminals in the posterior pituitary.

We have recently reported the dendritic location of $\mathrm{BCl}$ RNA, a short nontranslatable RNA polymerase III transcript (Tiedge et al., 1991, 1992). BCl RNA is expressed almost exclusively in nerve cells (DeChiara and Brosius, 1987; McKinnon et al., 1987; Tiedge et al., 1991) where it is located in somatic and/or dendritic domains (Tiedge et al., 1991, 1992). Recent data (Kobayashi et al., 1991, 1992; Cheng et al., 1992) indicate that $\mathrm{BCl}$ RNA is complexed with proteins to form a ribonucleoprotein particle (RNP), and it has been suggested that the BC1 RNP operates in dendritic domains of neurons, assisting in local protein synthetic mechanisms. Here we present evidence that $\mathrm{BC} 1$ RNA is transported along the hypothalamo-neurohypophyscal tract to axonal nerve endings in the posterior pituitary. Colocalization of BC1 RNA with several neuronal mRNAs in such terminals further supports the notion of $\mathrm{BC} 1 \mathrm{RNA}$ participating in translation-related processes in extrasomatic domains of nerve cells.

\section{Materials and Methods}

Animals. For routine in situ hybridization, pituitaries were prepared from adult male Wistar and adult male Sprague-Dawley rats, with identical results. Adult male PanWistar rats were used to generate experimental diabetes insipidus. In this paradigm, hypothalamo-neurohypophyseal tracts werc physically disconnected by paired electrical lesions, as described earlier (Thorn et al., 1965; Mohr et al., 1990). Briefly, the tip of a unipolar electrode was placed midway between the optic chiasm and the ventromedial nuclei, the other electrode being placed in the rectum. A lesion was produced by applying $3-4 \mathrm{~mA}$ for $20 \mathrm{sec}$. The same procedure was performed on the other side. Lesion procedures were repeated after $10 \mathrm{~d}$. For sham operations, animals were subjected to the same procedure, except that no current was applied. For this study, a total of six animals was operated: three animals were lesion operated, and three animals were sham operated. Daily water consumption was monitored, and diuresis and urine osmolality were measured in metabolic cages. Animals were killed $10 \mathrm{~d}$ after the second operation. Tissue from nonoperated, sham-operated, and lesion-operated animals was processed for in situ hybridization as described earlier (Tiedge, 1991; Tiedge ct al., 1991). Sections were also generated for immunocytochemical control experiments in which an antibody directed against vasopressin (ICN Biochemicals) was used to confirm the elimination of vasopressin containing axons in posterior lobes of lesionoperated animals and the survival of such axons in posterior lobes of sham-operated animals. An antibody against glial fibrillary acidic protein (GFAP; Boehringer Mannheim) was used to confirm the presence of GFAP-positive pituicytes in the posterior lobes of normal, shamoperated, and lesion-operated animals.

In situ hybridization. ${ }^{3} \mathrm{H}$ - and ${ }^{35} \mathrm{~S}$-labeled RNA probes were used in this study. Sense and antisense probes specific for $\mathrm{BC} 1$ RNA were gen- erated from plasmid pMK1 (Tiedge et al., 1991). Probes for high-molecular-mass MAP2 mRNA were generated as described by Kleiman et al. (1990); the antisense probe recognizes specifically the dendritic mRNA for high-molecular-mass MAP2, but not the mRNA for low-molecularmass MAP2 (Garner et al., 1988). Probes for GAP-43 (growth-associated protein 43) mRNA were generated as described earlier (Tiedge et al., 1991). In situ hybridization was performed as describcd (Ticdge, 1991; Tiedge et al., 1991). Prehybridization and hybridization were carried out at $50^{\circ} \mathrm{C}$. Tissue sections were exposed to autoradiographic NTB2 emulsion (Eastman Kodak) for the times indicated in the figure captions.

\section{Results}

In the adult rat brain, $\mathrm{BC} 1 \mathrm{RNA}$ was detected at significant levels in several hypothalamic nuclei. In the supraoptic nucleus (SON), in situ hybridization with probes specific for BC1 RNA produced a massive labeling signal (Fig. $1 A$ ), making the SON in fact one of the most intensely labeled areas of the rat brain. Magnocellular neurons in the SON extend axons to the posterior lobe of the pituitary (Palay, 1957). The $\mathrm{BCl}$ hybridization signal was seen overlying both cell bodies and neuropil areas (Fig. $1 A$ ). The observed labeling pattern in the SON thus suggests that BCl RNA is distributed to somatic and dendritic domains of nerve cells, similar to the general distribution in other areas of the adult rat brain (Tiedge et al., 1991). Adjacent white matter areas of the optic nerve showed comparatively little specific labeling (Fig. 1A). Significant $\mathrm{BC} 1$ hybridization, albeit at levels slightly lower than in the SON, was also observed in the paraventricular hypothalamic nuclei, where both magnocellular and parvocellular elements contribute to the labeling signal (not shown).

In the pituitary, strong BC1 labeling intensities were detected only in the postcrior lobc (Figs. $1 D-F$ ). Little specific labeling was evident in the anterior lobe, and only a few isolated cells in the intermediate lobe, often in the vicinity of blood vessels, were labeled above background (data not shown). In the posterior lobe, autoradiographic silver grains indicating the presence of BC1 RNA appeared to be clustered in discrete areas (Fig. $1 E$ ). Such clusters were prominent in areas distal to pituicyte cell bodies; significantly fewer silver grains were observed directly overlying pituicyte perikarya (pituicytes are astrocyte-like glial cells in the posterior pituitary; see Wittkowski, 1986, for review). Clusters of autoradiographic silver grains were often seen in the vicinity of blood vessels. Such areas are frequented by axons of hypothalamic magnocellular neurons $(\mathrm{Pa}-$ lay, 1957), and grain clusters may represent collections of axons that are enriched in $\mathrm{BC} 1 \mathrm{RNA}$. In contrast to BC1 RNA, little or no specific labeling could be detected in the posterior pituitary with a probe against dendritic MAP2 mRNA or with a probe against GAP-43 mRNA (Figs. $1 G-I$ ). A low but significant labeling signal indicating the presence of MAP2 $\mathrm{mRNA}$ was, however, evident in the intermediate lobe (Fig. $1 G$ ). Both MAP2 mRNA and GAP-43 mRNA were detectable at substantial levels in hypothalamic nuclei, including supraoptic and paraventricular nuclei (not shown); while GAP-43 mRNA was restricted to neuronal perikarya, MAP2 mRNA labeling was also detectable in neuropil areas.

Neurosecretory nerve endings in the posterior pituitary are often in contact with pituicyte processes and are sometimes physically engulfed by them, in particular during periods of low hormone release (Tweedle and Hatton, 1980a,b). An unequivocal attribution of autoradiographic BCl labeling signal to axonal processes in the posterior pituitary is therefore difficult when based on the light microscopic inspection of pituitary 


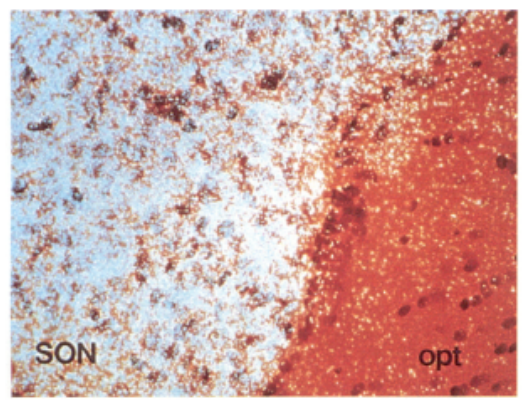

A
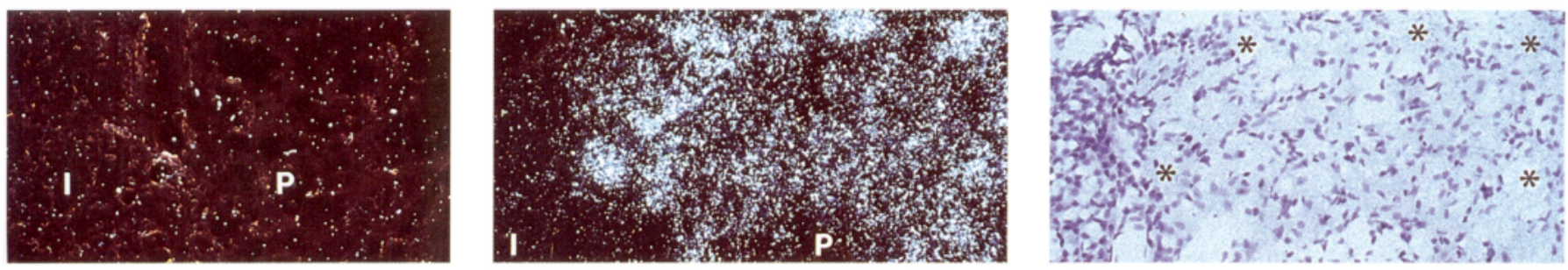

D
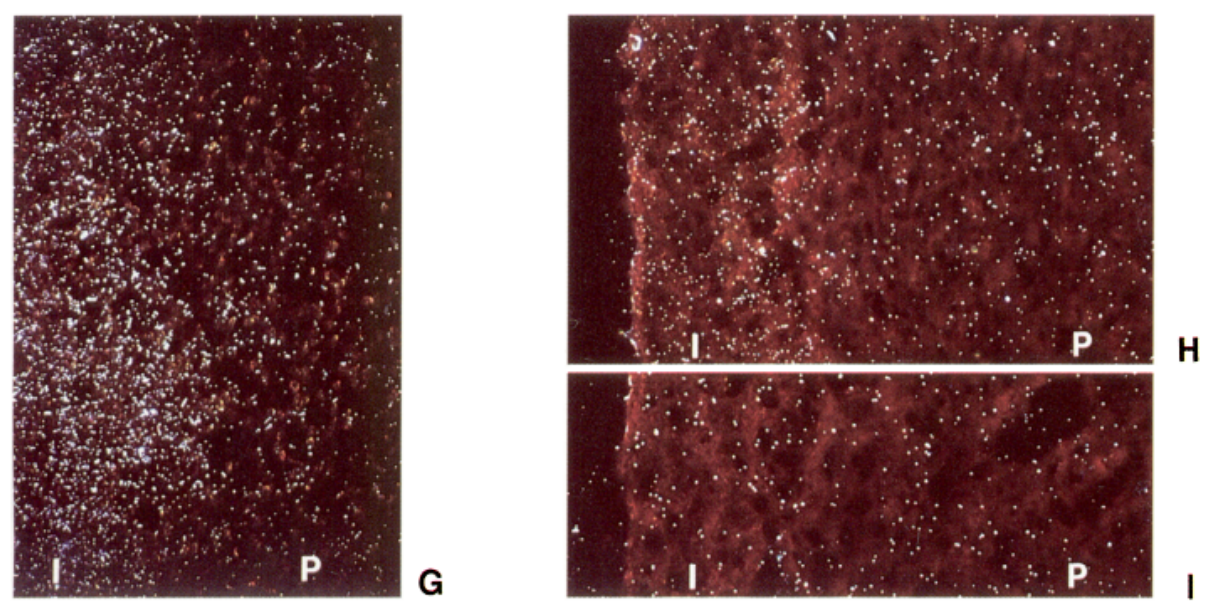

Figure 1. Expression of BC1 RNA in the hypothalamo-neurohypophyseal system. White silver grains result from emulsion autoradiography and indicate labeling intensities. Probes were either ${ }^{35} \mathrm{~S}$-labeled $(A, D-I)$ or ${ }^{3} \mathrm{H}$-labeled $(B$ and $C) . A, \mathrm{BC} 1 \mathrm{RNA}$ labeling in the SON and in the optic nerve; epiluminescence photomicrograph. $B$ and $C$, BCl labeling in the median eminence; $B$, dark-field photomicrograph; $C$, bright-field photomicrograph. Open arrows in $C$ demarcate the zona interna. $3 V$, third ventricle. $D-I$, Sections through the intermediate $(I)$ and posterior $(P)$ lobe of the pituitary. $D, \mathrm{BC} 1$ RNA sense-strand control. $E$ and $F, \mathrm{BC} 1 \mathrm{RNA}$ labeling; $E$, dark-field optics; $F$, bright-field optics. Note the clustered BC1 RNA labeling signal (marked by asterisks in $F$ ). $G$, dark-field photomicrograph, showing the labeling pattern of high-molecular-mass MAP2 mRNA. In addition, MAP2 mRNA was detected in the anterior lobe at appreciable levels (not shown). $H$, dark-field photomicrograph, showing the labeling pattern of GAP-43 mRNA. I, dark-field photomicrograph, GAP-43 mRNA sense-strand control. MAP2 mRNA sense-strand controls revealed equally low background levels (not shown). Exposure times: $A, 4 \mathrm{~d} ; B$ and $C, 21 \mathrm{~d} ; D-F, 7 \mathrm{~d} ; G, 21 \mathrm{~d} ; H$ and $I$, 40 d. Sections were counterstained with cresyl violet. Microscopes: Leitz Orthoplan (epiluminescence optics) and Nikon Microphot-FX (dark-field and bright-field optics). Scale bar, $15 \mu \mathrm{m}$ for $A, 45 \mu \mathrm{m}$ for $B-I$.

sections alone. For this reason, we probed cross sections through the neural stalk for the presence of BC1 RNA. The neural stalk contains the shafts of hypothalamo-neurohypophyseal axons, and BCl RNA should be detectable along these shafts if it is axonally transported to the nerve endings in the posterior pituitary rather than being synthesized locally by pituicytes or other non-neuronal cells. As shown in Figure $1, B$ and $C, \mathrm{BC} 1$ RNA was indeed detected in the median eminence, although labeling intensities were significantly lower than in either the SON or the posterior pituitary. Labeling was strongest in the central zona interna of the median eminence; little specific labeling was observed in the peripheral zona externa. Most hypothalamo-neurohypophyseal axons are contained in the zona interna (Holmes and Ball, 1974; Wittkowski, 1980). Our observations are also consistent with a previous report that has demonstrated that axonally transported vasopressin mRNA is concentrated in the zona interna (Mohr et al., 1991).

While these data indicate that hypothalamo-neurohypophyseal axons contain BC1 RNA, they do not rule out the possibility that other, non-neuronal elements in the neurohypophysis may also contribute to the labeling signal. We therefore disconnected the hypothalamo-neurohypophyseal tract in vivo in order to determine whether BC1 RNA is present exclusively in axonal nerve endings or also in non-neuronal cells such as pituicytes. Neurosecretory axons have been shown to disappear completely from the posterior pituitary within $10 \mathrm{~d}$ after such disconnec- 


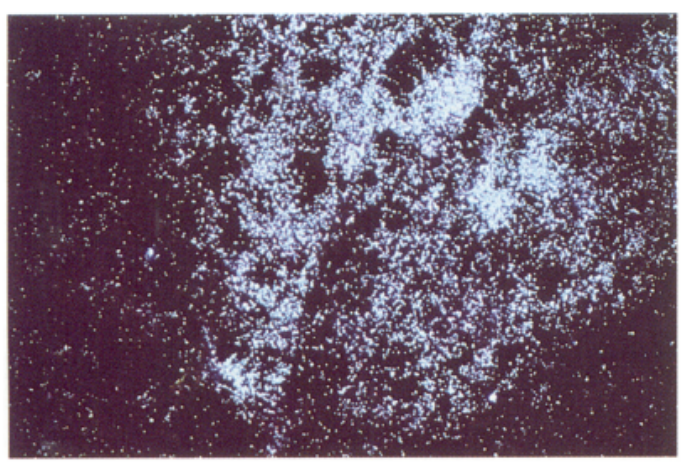

A

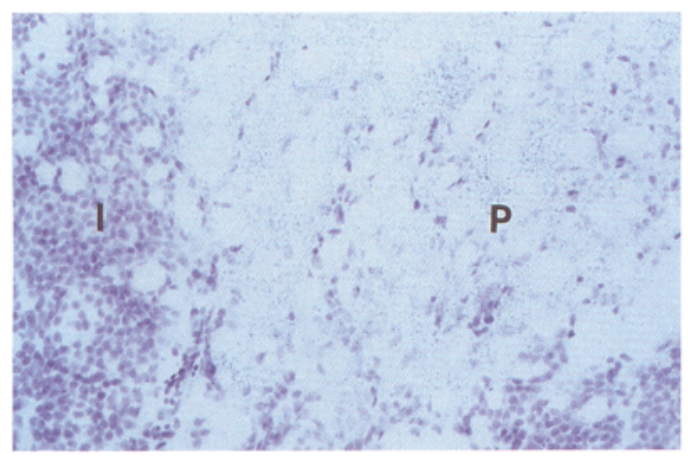

B

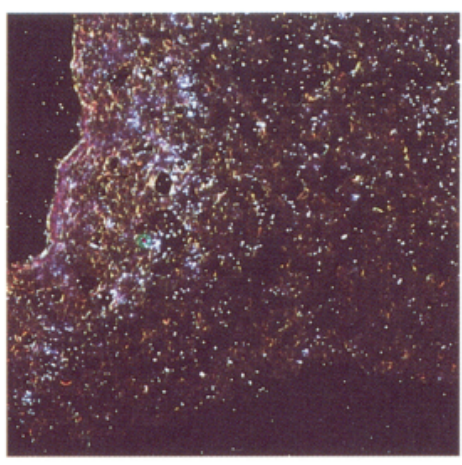

C

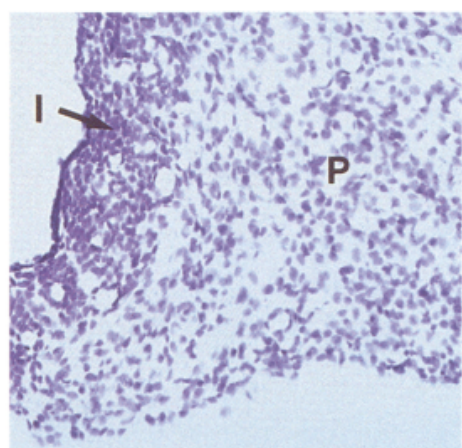

D

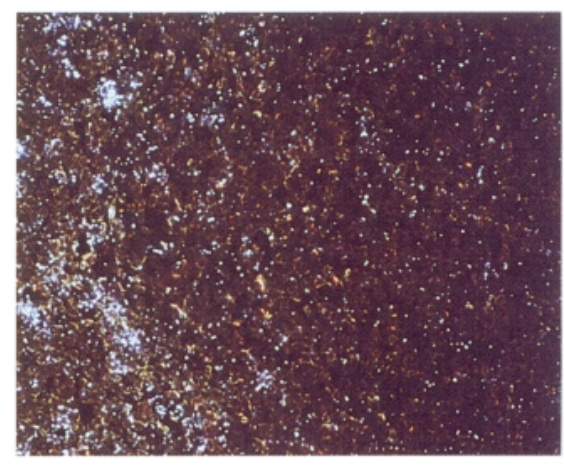

E

Figure 2. Disconnection of the hypothalamo-neurohypophyseal tract: distribution of BC1 RNA in sham-operated rats $(A, B)$ and in lesion-operated rats $(C$ and $D, E$ and $F) . A, C, E$, Dark-field photomicrographs; $B, D, F$, bright-field photomicrographs. White autoradiographic silver grains in the dark-field photomicrographs indicate $\mathrm{BC} 1$ labeling intensities. $C$ and $D$, and $E$ and $F$ are from two independently lesion-operated animals. Exposure times: $A$ and $B, 7 \mathrm{~d} ; C-F, 21 \mathrm{~d} . C-F$ were exposed three times longer than $A$ and $B$ in order to demonstrate the lack of specific BC1 labeling in the posterior lobe. A slight increase in $\mathrm{BCl}$ expression levels in some cells of the intermediate lobe may be due to denervation, for example, due to a loss of inhibitory input (see also Seger et al., 1987). Morphological changes in the posterior lobe following disconnection of the neural stalk are discussed by Dellman (1973). $I$, intermediate lobe; $P$, posterior lobe. Sections were counterstained with cresyl violet. Nikon Microphot-FX. Scale bar, $45 \mu \mathrm{m}$.

tion, leaving only non-neuronal components such as glial-like pituicytes, perivascular cells, and connective tissue (Dellman et al., 1973; Lightman et al., 1983; for reviews, see Dellman, 1973; Wittkowski, 1980).

Hypothalamo-neurohypophyseal tracts were physically disconnected in vivo as described in a previously established electrical lesion protocol (Thorn et al., 1965). Experimental diabetes insipidus was ascertained, and the complete loss of vasopressincontaining axons from the posterior lobe was confirmed as described in Materials and Methods. Ten days after the second operation, animals were killed, and pituitaries were dissected and processed for in situ hybridization (Fig. 2). In pituitaries of lesion-operated animals, no significant $\mathrm{BCl}$ labeling signal was detectable in the posterior lobes even if sections had been deliberately overexposed to autoradiographic emulsion in order to reveal low residual levels of BCl RNA (Figs. $2 C-F$ ). In contrast, a strong $\mathrm{BCl}$ signal was observed in posterior pituitaries from sham-operated animals (Figs. $2 A, B$ ). BC1 labeling intensities in the sham-operated animals were at the same high levels that are typical of naive nonoperated animals, indicating that the sham operation did not affect the delivery of BC1 RNA to the posterior pituitary. Taken together, these results suggest that the accumulation of $\mathrm{BC} 1 \mathrm{RNA}$ in the posterior pituitary is prevented by disconnection of the hypothalamo-neurohypophyseal tract, and they are thus consistent with the view that BC1 RNA is synthesized in magnocellular neurons of the hypothalamus and transported along their axons to the neurosecretory terminals in the posterior lobe of the pituitary.

\section{Discussion}

In this report, we have localized neural BCl RNA to the posterior lobe of the pituitary and to the neural stalk. Our experimental strategy was based on in situ detection of target RNAs rather than on extraction paradigms. This approach not only provides the necessary high spatial resolution, but also minimizes the risk of local cross-contamination that may pose potential problems with RNA extraction routines, especially when followed by PCR (polymerase chain reaction)-based amplification schemes.

The $\mathrm{BCl}$ labeling pattern that is described here is indicative of an axonal distribution of the RNA: the in situ hybridization signal was most intense in areas where neurosecretory axons are concentrated. Disconnection of the hypothalamo-neurohypophyseal tract resulted in the complete elimination of BC1 RNA from the posterior pituitary. Similar data have previously been obtained with mRNAs that are axonally transported (Mohr et al., 1990, 1991). It could be argued that the loss of labeling signal for such RNAs following disconnection of hypothalamoneurohypophyseal axons might be due to a disruption of the delivery of hypothetical factors necessary for transcription of 
those RNAs in cells of the posterior pituitary, rather than to a disruption of the delivery of the RNAs themselves. However, the absence of the corresponding primary transcripts from the posterior pituitaries of nonoperated animals is at variance with such assumption (Mohr et al., 1991). In conclusion, we interpret our results to indicate that BC1 RNA is synthesized in the cell bodies of hypothalamic neurons and is subsequently transported, within axons of the hypothalamo-neurohypophyseal tract, to the neurosecretory nerve endings in the posterior pituitary. This transport appears to be specific since neither dendritic MAP2 mRNA nor somatic GAP-43 mRNA could be detected in the posterior pituitary at significant levels. It remains to be determined in future experiments whether axonal RNA transport is cytoskeleton and/or vesicle associated.

It has been shown in previous studies that BC1 RNA is located in dendritic domains of a large subset of neurons in the rat nervous system (Tiedge et al., 1991, 1992), and it has been suggested that a BC1 RNP may interact with other RNAs/RNPs in postsynaptic compartments in translation-related processes (Tiedge et al., 1991). Recent results indicate that BC1 RNA is a prominent component of isolated dendritic spines (Chicurel et al., 1993) and of synaptodendrosomes (Rao and Steward, 1993), where it is colocalized with dendritic mRNAs. This colocalization is further evidence to support a role of BC.1 RNA in synapse-associated protein synthesis. The recent data are in line with earlier electron microscopic studies that have demonstrated that polyribosomes are located at the base or within the head of dendritic spines in dentate granule cells of the hippocampus (Steward and Levy, 1982; Steward and Reeves, 1988). In summary, these data indicate a possible interplay of various types of RNAs, including BC1 RNA, in local protein synthesis in postsynaptic dendritic compartments.

Little, if any, BC1 RNA was detected in earlier studies in axon-containing white matter areas in the rat nervous system (Tiedge et al., 1991) or along axonal processes of either hippocampal or sympathetic neurons in primary culture (C. Banker, J. Brosius, D. Higgins, and H. Tiedge, unpublished observations). While these data still left room for the possibility that BCl RNA might be sequestered in axonal terminals, no model system, either in vivo or in vitro, has been described to date where this was actually observed. At the same time, axonal terminals have generally been believed to lack protein synthetic capacity, a feature that would fundamentally distinguish them from somatodendritic domains (for reviews, see Ginzburg, 1991; Steward and Banker, 1992). Neurosecretory nerve endings of hypothalamo-neurohypophyseal axons so far provide the only exception, at least in mammals, to this rule. Four mRNAs, three of them encoding neuropeptides and the other one a cytoskeletal protein, as well as BCl RNA have now been shown to be transported to axonal nerve endings in the posterior pituitary. To our present knowledge, dendritic mRNAs and axonal mRNAs belong to distinct nonoverlapping families. $\mathrm{BCl}$ RNA is thus the only RNA at this time that has been identified both in dendritic and in axonal domains.

While the presence of RNAs in neurosecretory terminals may be a feature that is unique to this type of axon, the colocalization of $\mathrm{BCl}$ RNA and mRNAs in such axonal domains is nevertheless intriguing and may be indicative of functional interrelations. The functional significance of the presence of RNAs in neurosecretory terminals is a matter of current debate (Jirikowski et al., 1990; Mohr et al., 1991). A consensus has not yet emerged as to whether mRNAs are actually translated in these terminals, and other components of the translational apparatus, as well as posttranslational processing machinery, have yet to be identified in such domains. However, should active protein synthesis in neurosecretory terminals indeed be established in future experiments, one might anticipate a role of BC1 RNA or of the respective BC1 RNP in local translation-associated processes in such axons. For example, BC1 RNA may assist, both in dendritic domains of various types of neurons and in axonal terminals of highly specialized nerve cells, in the transport and docking of locally translated mRNAs; alternatively or in addition, it may mediate arrest and reinitiation of translation in extrasomatic domains, analogous to the function of the signal recognition particle in the cell soma. Such processes may be subject to local regulation, under the influence, for example, of transsynaptic activity or hormone action (see Bondy ct al., 1988, for an example of local hormonal regulation in the posterior pituitary). In summary, it is conceivable that BC1 RNA performs translation-related functions both in conventional dendritic protein synthesis and in individual cases of axonal protein synthesis. The delineation of the functional role of $\mathrm{BCl}$ RNA and the prospective BC1 RNP may thus provide important clues with respect to mechanistic aspects of both dendritic and axonal RNA transport and translation.

\section{References}

Benson DL, Isackson PJ, Gall CM, Jones EG (1991) Differential effects of monocular deprivation on glutamic acid decarboxylase and type II calcium-calmodulin-dependent protein kinase gene expression in the adult monkey cortex. J Neurosci 11:31-47.

Berleth T, Burri M, Thoma G, Bopp D, Richstein S, Frigerio G, Noll M, Nüsslein-Volhard C (1988) The role of localization of bicoid RNA in organizing the anterior pattern of the Drosophila embryo. EMBO J 7:1749-1756.

Bondy CA, Gainer H, Russel JT (1988) Dynorphin A inhibits and naloxone increases the electrically stimulated release of oxytocin but not vasopressin from the terminals of the neural lobe. Endocrinology 122:1321-1327.

Bruckenstein DA, Lein PJ, Higgins D, Fremeau RT Jr (1990) Distinct spatial localization of specific mRNAs in cultured sympathetic neurons. Neuron 5:809-819.

Burgin KE, Waxham MN, Rickling S, Westgate SA, Mobley WC, Kelly PT (1990) In situ hybridization histochemistry of $\mathrm{Ca}^{2+} /$ calmodulindependent protein kinase in developing rat brain. J Neurosci 10:17881798.

Cheng H, Bjerknes M (1989) Asymmetric distribution of actin mRNA and cytoskeletal pattern generation in polarized epithelial cells. J Mol Biol 210:541-549.

Cheng JG, Tiedge H, Brosius J (1992) Characterization of BC1 scRNP, a brain-specific cytoplasmic ribonucleoprotein complex. Soc Neurosci Abstr 18:624.

Chicurel ME, Terrian DM, Potter H (1993) mRNA at the synapse: analysis of a preparation enriched in hippocampal dendritic spines. $\mathrm{J}$ Neurosci, in press.

Colman DR, Kreibich G, Frey AB, Sabatini DD (1982) Synthesis and incorporation of myelin polypeptides into CNS myelin. J Cell Biol 95:598-608.

DeChiara TM, Brosius J (1987) Neural BC1 RNA: cDNA clones reveal nonrepetitive sequence content. Proc Natl Acad Sci USA 84:26242628.

Dellman H-D (1973) Degeneration and regeneration of neurosecretory systems. Int Rev Cytol 36:215-315.

Dellman H-D, Stoeckel ME, Porte A, Stutinsky F, Klein MJ, Chang N, Addlinger HK (1973) Ultrastructure of the rat neural lobe following interruption of the hypophysial stalk. Anat Rec 175:305.

Dugich-Djordjevic MM, Tocco G, Willoughby DA, Najm I, Pasinetti G, Thompson RF, Baudry M, Lapchak PA, Hefti F (1992) BDNF mRNA expression in the developing rat brain following kainic acidinduced seizure activity. Neuron 8:1127-1138.

Ephrussi A, Dickinson LK, Lehmann R (1991) oskar organizes the 
germ plasm and directs localization of the posterior determinant na nos. Cell $66: 37-50$.

Garner CC, Tucker RP, Matus A (1988) Selective localization of messenger RNA for cytoskeletal protein MAP2 in dendrites. Nature 336: 674-677.

Gavis ER, Lehmann R (1992) Localization of nanos RNA controls embryonic polarity. Cell 71:301-313.

Ginzburg 1 (1991) Neuronal polarity: targeting of microtubule components into axons and dendrites. Trends Biochem Sci 16:257-261.

Holmes RL, Ball JN (1974) The pituitary gland. A comparative account. Cambridge: Cambridge UP.

Hoock TC, Newcomb PM, Herman IM (1991) $\beta$ actin and its mRNA are localized at the plasma membrane and the regions of moving cytoplasm during the cellular response to injury. J Cell Biol 4:653664.

Jirikowski GF, Sanna PP, Bloom FE (1990) mRNA coding for oxytocin is present in axons of the hypothalamo-neurohypophyseal tract. Proc Natl Acad Sci USA 87:7400-7404.

Kim-Ha J, Smith JL, Macdonald PM (1991) oskar mRNA is localized to the posterior pole of the Drosophila oocyte. Cell 66:23-35.

Kislauskis EH, Singer RH (1992) Determinants of mRNA localization. Curr Opin Cell Biol 4:975-978.

Kleiman R, Banker G, Steward O (1990) Differential subcellular localization of particular mRNAs in hippocampal neurons in culture. Neuron 5:821-830.

Kobayashi S, Goto S, Anzai K (1991) Brain-specific small RNA transcript of the identifier sequences is present as a $10 \mathrm{~S}$ ribonucleoprotein particle. J Biol Chem 266:4726-4730.

Kobayashi S, Higashi N, Susuki K, Goto S, Yumoto K, Anzai K (1992) The $10 \mathrm{~S}$ BC-1 ribonuclcoprotein particle contains identifier sequence-binding proteins that interact with an array of GCAAG/ CTTGC motifs between split promoter sequences for RNA polymerase III. J Biol Chem 267:18291-18297.

Lawrence JB, Singer RH (1986) Intracellular localization of messenger RNAs for cytoskeletal proteins. Cell 45:407-415.

Lehman E, Hänze J, Pauschinger M, Ganten D, Lang RE (1990) Vasopressin mRNA in the neurolobe of the rat pituitary. Neurosci Lett 111:170-175.

Levy A, Lightman SL, Carter D, Murphy D (1990) The origin and regulation of posterior pituitary vasopressin ribonucleic acid in osmotically stimulated rats. J Neuroendocrinol 2:329-334.

Lightman SL, Ninkovic M, Hunt SP (1983) Neurohypophysial opiate receptors: are they on pituicytes? In: Progress in brain research, Vol 60 , The neurohypophysis: structurc, function and control (Cross BA, Leng G, eds), pp 353-356. Amsterdam: Elsevier.

McCabe JT, Lehman E, Chastrette N, Hänze J, Lang RE, Ganten D, Pfaff DW (1990) Detection of vasopressin mRNA in the neurointermediate lobe of the rat pituitary. Mol Brain Res 8:325-329.

McKinnon RD, Danielson P, Brow MAD, Bloom FE, Sutcliffe JG (1987) Expression of small cytoplasmic transcripts of the rat identifier element in vivo and in cultured cells. Mol Cell Biol 7:2148-2154

Melton DA (1987) Translocation of a localized maternal mRNA to the vegetal pole of Xenopus oocytes. Nature 328:80-82.

Mohr E, Richter D (1992) Diversity of mRNAs in the axonal compartment of peptidergic neurons in the rat. Eur J Neurosci 4:870 876.

Mohr E, Zhou A, Thorn NA, Richter D (1990) Rats with physically disconnected hypothalamo-pituitary tracts no longer contain vasopressin-oxytocin gene transcripts in the posterior pituitary lobe. FEBS Lett 263:332-336.

Mohr E, Fehr S, Richter D (1991) Axonal transport of neuropeptide encoding mRNAs within the hypothalamo-hypophyseal tract of rats. EMBO J 10:2419-2424.

Murphy D, Levy A, Lightman S, Carter D (1989) Vasopressin RNA in the neural lobe of the pituitary: dramatic accumulation in response to salt loading. Proc Natl Acad Sci USA 86:9002-9005.
Palay SL (1957) The fine structure of the neurohypophysis. In: Ultrastructure and cellular chemistry of neural tissue (Welsch $\mathrm{H}$, ed), pp 31-49. New York: Hoeber.

Rao A, Steward O (1991) Evidence that protein constituents of postsynaptic membrane specializations are locally synthesized: analysis of proteins synthesized within synaptosomes. J Neurosci 11:28812895.

Rao A, Steward O (1993) Evaluation of RNAs present in synaptodendrosomes: dendritic, glial, and neuronal cell body contribution. $\mathrm{J}$ Neurochem, in press.

Sarthy PV, Fu M, Huang J (1989) Subcellular localization of an intermediate filament protein and its mRNA in glial cells. Mol Cell Biol 9:4556-4559.

Seger MA, Kiss JZ, van Tool HHM, Burbach JPH (1987) Biosynthesis of proopiomelanocortin is increased in the rat intermediate pituitary following denervation. Neurosci Lett 83:149-155.

Steward O, Banker GA (1992) Getting the message from the gene to the synapse: sorting and intracellular transport of RNA in neurons. Trends Neurosci 15:180-186.

Steward O, Levy WB (1982) Preferential localization of polyribosomes under the base of dendritic spines in granule cells of the dentate gyrus. J Neurosci 2:284-291.

Steward O, Reeves TM (1988) Protein-synthetic machinery beneath postsynaptic sites on CNS neurons: association between polyribosomes and other organelles at the synaptic site. J Neurosci 8:176184.

Strong MJ, Svedmyr A, Gajdusek DC, Garruto RM (1990) The temporal expression of amyloid precursor protein mRNA in vitro in dissociated hippocampal neuron cultures. Exp Neurol 109:171-179.

Thorn N $\Lambda$, Smith MW, Skadhauge E (1965) The antidiuretic effect of intravenous and intracarotid infusion of calcium chloride in hydrated rats. J Endocrinol 32:161-165.

Tiedge $\mathbf{H}$ (1991) The use of UV light as a cross-linking agent for cells and tissue sections in in situ hybridization. DNA Cell Biol 10:143147.

Tiedge H, Fremeau RT Jr, Weinstock PH, Arancio O, Brosius J (1991) Dendritic location of neural BC1 RNA. Proc Natl Acad Sci USA 88: 2093-2097.

Tiedge H, Dräger UC, Brosius J (1992) Murine BC1 RNA in dendritic fields of the retinal inner plexiform layer. Neurosci Lett 141:136-138.

Torre ER, Steward O (1992) Demonstration of local protein synthesis within dendrites using a new cell culture system which permits the isolation of living axons and dendrites from their cell bodies. J Neurosci $12: 762-772$.

Trapp BD, Moench T, Pulley M, Barbosa E, Tennekoon G, Griffin J (1987) Spatial segregation of mRNA encoding myelin-specific proteins. Proc Natl Acad Sci USA 84:7773-7777.

Trimmer PA, Phillips LL, Steward O (1991) Combination of in situ hybridization and immunocytochemistry to detect messenger RNAs in identified CNS neurons and glia in tissue culture. J Histochem Cytochem 7:891-898.

Tweedle CD, Hatton GI (1980a) Evidence for dynamic interactions between pituicytes and neurosecretory axons in the rat. Neuroscience 5:661-667.

Tweedle CD, Hatton GI (1980b) Glial cell enclosure of neurosecretory endings in the neurohypophysis of the rat. Brain Res 192:555-559.

Webster HdeF, Lamperth L, Favilla JT, Lemke G, Tesin D, Manuelidis L (1987) Use of biotinylated probc and in situ hybridization for light and electron microscopic localization of $\mathrm{P}_{0} \mathrm{mRNA}$ in myelinforming Schwann cells. Histochemistry 86:441-444.

Wittkowksi W (1980) Glia der Neurohypophyse. In: Handbuch der mikroskopischen Anatomie des Menschen, Vol 4 (Oksche A, ed), pp 667-756. Berlin: Springer.

Wittkowski W (1986) Pituicytes. In: Astrocytes, Vol 1 (Fedoroff S, Vernadakis A, eds), pp 173-208. Orlando, FL: Academic. 